was higher for the most stringent definitions. However, this also meant that, for the most stringent criteria, many patients in non-remission had $\mathrm{HAQ} \leq 0.5$. The strongest degree of association between remission and $\mathrm{HAQ} \leq 0.5$ was observed for the SDAI. However, only minor differences were noted between definitions (table 1). Sensitivity analyses yield similar results (not shown).

Conclusions: The various remission definitions confirmed their validity in terms of physical function in a large international clinical practice setting. However, many patients in non-remission will still have good functional status and being in clinical remission does not equate to having $H A Q \leq 0.5$. A multidimensional approach should be taken to help patients achieve this functional goal. Achievement of remission according to any of the indices is more important than the use of a specific index.

Disclosure of Interest: None declared

DOI: 10.1136/annrheumdis-2017-eular.3929

\section{FRI0127 OUTCOMES OF DISEASE ACTIVITY IN A 5-YEAR LARGE COHORT OF RHEUMATOID ARTHRITIS PATIENTS TREATED UNDER TREAT TO TARGET RECOMMENDATIONS AND A MULTIDISCIPLINARY CARE MODEL - A REAL-LIFE EXPERIENCE}

P. Santos-Moreno ${ }^{1}$, D. Gomez ${ }^{1}$, E. Castillo ${ }^{1}$, R. Giraldo ${ }^{1}$, G. Ballesteros ${ }^{1}$, L. Villarreal ${ }^{2}$, J. Bello $^{3}$, D. Buitrago-Garcia ${ }^{3} .{ }^{1}$ Rheumatology; ${ }^{2}$ Psychology and processes; ${ }^{3}$ Epidemiology, Biomab, Center for Rheumatoid Arthritis, Bogota, Bogota, Colombia

Background: Treat to Target (T2T) strategy becomes from the need to develop therapeutic targets and tools to achieve defined outcomes in rheumatoid arthritis (RA), this strategy has become recognized as a standard of good practice embodying the principle that rapid attainment of remission, or low disease activity, can halt joint damage and maintain good quality of life.

Objectives: The aim of this study was to describe global change in Disease Activity Score 28 (DAS28) using T2T strategy for a 60 month period in a large cohort of patients from a Colombian specialized in RA center.

Methods: A descriptive cohort study was conducted. Medical records of patients from specialized in RA center were reviewed; those patients were followed-up under T2T standards and a multidisciplinary approach. Each patient had a minimum of 6 follow-up visits. Clinical follow-up was designed by the authors according to DAS28 as follows: every $3-5$ weeks (DAS28 >5.1), every 7-9 weeks (DAS28 $\geq 3.1$ and $\leq 5.1$ ), and every $11-13$ weeks (DAS28 $<3.1$ ). Tender joint count (TJC), swollen joint count (SJC) and DAS28 were measured on each visit. Therapy had to be adjusted with DAS28 $>3.2$ unless patient's conditions don't permit it; we considered this follow-up type as implementation of a T2T strategy in patients with RA. We divided patients in four groups: remission (REM), low disease activity (LDA), moderate disease activity (MDA) and severe disease activity (SDA) patients and the aim of the study was to look at what percentage of patients who were in moderate or severe disease activity reached a low disease activity or remission. Descriptive epidemiology was done, percentages and averages were calculated; the median of each variable was analyzed using t-Student assuming normality for DAS28 distribution and the level activity disease was analyzed using Pearson's statistics.

Results: 3618 patients meet the inclusion criteria. $72 \%$ were receiving conventional DMARDs therapy and $28 \%$ were receiving biological therapy. $83 \%$ were woman and $17 \%$ were men. Mean age was 61 years \pm 11 . Mean DAS28 at beginning was $3.3 \pm 1.3$ and at the end of five year period was $2.8 \pm 0.7$. The difference of medians for DAS28 at begging and at the end showed improvement with statistical significance $(p<0.00)$. It was found a global increase in the percentage of patients in remission and LDA and decrease in moderate and severe disease activity groups (from $31 \%$ to $19 \%$ and from $12 \%$ to $2 \%$ respectively) with statistical significance.

\begin{tabular}{|l|r|r|r|r|}
\hline ACTIMTYLEVEL & \multicolumn{1}{|l|}{ TME 0 n(\%) } & $\begin{array}{l}2011-2012 \\
n(\%)\end{array}$ & $2013-2014(\%)$ & $2015-2016(\%)$ \\
\hline REM & $1512(42)$ & $1548(43)$ & $1751(48)$ & $1826(50)$ \\
\hline LDA & $536(15)$ & $955(26)$ & $969(27)$ & $1033(29)$ \\
\hline MDA & $1128(31)$ & $875(24)$ & $809(22)$ & $694(19)$ \\
\hline SDA & $442(12)$ & $240(7)$ & $89(2)$ & $65(2)$ \\
\hline
\end{tabular}

Conclusions: This study show evidence of an improvement in DAS28 and level of disease activity in a cohort of RA patients from a specialized center in Colombia treated under recommendations of T2T strategy; it was found a global increase in the percentage of patients in remission (REM) and decrease in moderate and severe disease activity groups. This revision shows the importance of T2T follow-up and a multidisciplinary treatment for the management or RA

Disclosure of Interest: None declared

DOI: 10.1136/annrheumdis-2017-eular.5589

\section{FRI0128 PRISM - PICTORIAL REPRESENTATION OF ILLNESS AND SELF MEASURE: THE USE OF A SIMPLE NON-VERBAL TOOL AS A PATIENT-CENTRED OUTCOME MEASURE IN EARLY RHEUMATOID ARTHRITIS COHORTS}

P.C. Taylor ${ }^{1}$, R. Alten ${ }^{2}$, B. Haraoui ${ }^{3}$, B. Amess ${ }^{1}$, J. Macdonald ${ }^{1}$, M. Truchon ${ }^{4}$, C. Pohl ${ }^{2}$, C. Swales ${ }^{1}$, Y. Kaneko ${ }^{5}$, T. Sensky ${ }^{6}$. ${ }^{1}$ Nuffield Department of
Orthopaedics, Rheumatology and Musculoskeletal Sciences, University of Oxford, Oxford, United Kingdom; ${ }^{2}$ Schlosspark-Klinik Charité, University Medicine Berlin, Berlin, Germany; ${ }^{3}$ Université de Montréal, Montreal; ${ }^{4}$ l'institut de Rhumatologie de Montréal, Montréal, Canada; ${ }^{5}$ Department of Internal Medicine, Keio University School of Medicine, Tokyo, Japan; ${ }^{6}$ Centre for Mental Health, Imperial College London, London, United Kingdom

Background: Treatment recommendations in early RA advocate a treat to target approach with the ideal goal of remission. But not all patients attain this goal. There is a need for outcome measures that are meaningful to patients and inform management of which alleviation of suffering is a key aim. PRISM ${ }^{1}$ is a novel, validated, brief method of measuring suffering consistent with Cassell's seminal conceptualisation ${ }^{2}$.

Objectives: To understand the relationships between a patient's perception of the totality of the impact of RA and commonly used clinical assessments of disease activity, depression and illness intrusiveness.

Methods: Basic sociodemographic and clinical data were collected from 182 RA patients from 3 international centres, assigned to one of four cohorts (two early RA and two established RA), at baseline, weeks 12 and 24. The two early RA cohorts (diagnosis $<2 \mathrm{yr}$ ) comprised Group 1 on stable treatment $(n=37)$ and Group 2 requiring csDMARD adjustment $(n=34)$. Using the IPRISM App on a tablet, all patients were asked to complete the basic PRISM task to measure self-illness separation (SIS). The smaller the SIS, the greater the person's perceived suffering. In the PRISM+ task, patients were asked to identify two valued aspects of their life at the moment $(X$ and $Y$ ) which bring pleasure, satisfaction, a sense of achievement, or a sense of purpose. The iPRISM App automatically records the distance between the centres of each of these disks and the Self disk to measure patients' perceptions of the intrusiveness of their illness on two personally valued aspects of their lives.

For both groups, direction of change in SIS and the PRISM+ measures were compared with direction of change in disease activity measures and patient global disease activity (ptGbl), assessed at wks 12 and 24, using the sign test.

Results: PRISM was easy to use and most patients understood the simple instructions. Of 182 patients at baseline, SIS showed significant correlations with ptGbl $\left(r_{s}=-0.48, p<0.0001\right)$, pain VAS $\left(r_{s}=-0.45, p<0.0001\right)$, PHQ9 $\left(r_{s}=-0.45\right.$, $p<0.0001)$ and illness intrusiveness scale $\left(r_{s}=-0.51, p<0.0001\right)$. Suffering was inversely correlated with the perceived controllability of the symptoms of RA; for Group 1, $r_{s}=0.41, p<0.0001$, for Group 2, $r_{s}=0.32, p<0.0001$.

In Group 2, SIS and DAS28-ESR showed small trends to improvement by wk 12 (DAS28-ESR $\Delta=-0.11, \mathrm{p}=0.557$; SIS $\Delta=1.7, \mathrm{p}=0.296$ ) with significant improvement by wk 24 (DAS28-ESR $\Delta=-0.82, p=0.002$; SIS $\Delta=3.85, p=0.029$ ). However, there was no significant improvement in the intrusiveness of the illness on the valued aspects of life over this time period (Actual $X, \Delta=-0.25, p=0.557$; Actual $\mathrm{Y}, \Delta=1.89, \mathrm{p}=0.169$ ).

Conclusions: PRISM is a novel PRO that quantifies factors salient to each individual with respect to the impact of RA and its treatment while allowing for incorporation of a wide range of such influences. It may have utility as an adjunct to disease activity measures in setting agreed personalised therapeutic targets.

References:

[1] T Sensky \& S Buchi. PLoS ONE 11(5):e0156284, 2016.

[2] EJ Cassell. NEJM 306:639-645,1982.

Acknowledgements: This work was financially supported by UCB in the context of an Investigator Initiated Study.

Disclosure of Interest: P. Taylor Grant/research support from: Celgene, Galapagos, GlaxoSmithKline, UCB, and Janssen, Consultant for: AbbVie, Bristol Myers Squibb, Eli Lilly and Company, GlaxoSmithKline, Merck, Pfizer, UCB, Biogen, Sandoz and Janssen, R. Alten: None declared, B. Haraoui: None declared, B. Amess: None declared, J. Macdonald: None declared, M. Truchon: None declared, C. Pohl: None declared, C. Swales: None declared, Y. Kaneko Grant/research support from: Eisai, AbbVie, Daiichisankyo, Speakers bureau: Astellas Pharma, Chugai Pharmaceutical Co, Ltd., Bristol-Myers K.K., Eisai Co., Ltd., Kissei Co., Ltd., Janssen Pharmaceutical K.K., Mitsubishi Tanabe Pharma Co., Pfizer Japan Inc., Santen Pharmaceutical Co., Taisho Toyama Pharma Co., and UCB, T. Sensky: None declared

DOI: 10.1136/annrheumdis-2017-eular.4450

\section{FRIDAY, 16 JUNE 2017}

Rheumatoid arthritis - comorbidity and clinical aspects

\section{FRI0129 COMPARATIVE SAFETY OF BIOLOGIC DMARD INITIATION IN RA: A POPULATION-BASED OBSERVATIONAL STUDY OF MALIGNANCY RISK}

S. Suissa ${ }^{1}$, S. Dell'Aniello ${ }^{1}$, T. Simon ${ }^{2}{ }^{1}{ }^{1}$ McGill University, Montreal, Canada; ${ }^{2}$ Bristol-Myers Squibb, Princeton, United States

Background: Patients (pts) with RA are at increased risk for some malignancies and the use of biologic (b)DMARDs has been reported to further increase this risk. ${ }^{1}$ Abatacept (ABA), the first selective T-cell co-stimulation modulator for RA treatment, is now often prescribed as a first-line bDMARD, but long-term effects are unknown. 